\title{
NAD(P)H:Quinone Oxidoreductase 1 Expression in Human Primary Melanotic Melanomas of the Skin
}

\author{
Francesco Zappa ${ }^{1 *}$, Timothy Ward ${ }^{1}$, Ennio Pedrinis ${ }^{2}$, Alan Mc Gown ${ }^{1}$ and Nicholas Thatcher ${ }^{1}$ \\ ${ }^{1}$ CRC Department of Drug Development, Paterson Institute for Cancer Research and Christie Hospital NHS Trust, Manchester, UK \\ ${ }^{2}$ Institute of Pathology of Southern Switzerland, Locarno, Switzerland
}

"Corresponding author: Francesco Zappa, Department of Medical Oncology, Clinica Luganese, 6903 Lugano, Switzerland, Tel: +4191960 8147 ; Fax: +41 91960 8580; Email: Francesco.zappa@clinicaluganese.ch

Rec date: Nov 15, 2013, Acc date: July 03, 2014, Pub date: July 05, 2014

Copyright: () 2014 Zappa F, et al. This is an open-access article distributed under the terms of the Creative Commons Attribution License, which permits unrestricted use, distribution, and reproduction in any medium, provided the original author and source are credited.

\begin{abstract}
$\mathrm{NAD}(\mathrm{P}) \mathrm{H}$ :quinone oxidoreductase 1 (NQ01; DT-diaphorase; DTD) is a two-electron reducing enzyme which is often over-expressed in cancers and can activate quinones to form cytotoxic species. This over-expression is used as target in the design of novel anti-cancer drugs. DTD is also expressed in normal tissues, but little is known about its "body mapping". Because of the dearth of information on the cell-specific expression of DTD in pigmentproducing cells of the skin, we analysed its expression in normal and tumoral samples. Twenty skin biopsies of primary malignant melanotic melanomas (ten with vertical invasion, ten with superficial spreading) were analysed by immunohistochemistry. In normal skin DTD expression was weak in all epidermal layers, including normal melanocytes. Malignant melanomas showed a very strong DTD expression in tumoral cells of all samples and in endothelial lining of peri-tumoral vessels.
\end{abstract}

These results suggest that DT-diaphorase may be a new marker that could be useful in determining the extent of a malignant melanocytic lesion, and also tend to support the potential of malignant melanomas as target for DTDdirected antitumour agents.

Keywords: DT-diaphorase; NQ01; Mitomycin toxicity; Quinones; Immunohistochemistry; Immunohistochemical marker; Malignant melanoma; Melanocytic lesion

\section{Introduction}

$\mathrm{NAD}(\mathrm{P}) \mathrm{H}$ :quinone oxidoreductase 1 (NQ01, DT-diaphorase, DTD) is a cytosolic enzyme that is known to catalyse a two-electron reduction of many xenobiotics, including some that are carcinogens [1-3] and some that are anti-neoplastic agents [4-6]. DT-diaphorase is able not only to reduce exogenous and endogenous quinones, and thereby to protect the cells against these reactive intermediates, but also to activate some quinones with cytostatic properties [7].

Compounds such as mitomycin C, streptonigrin, MeDZQ, E09, tirapazamine and RH1 are efficiently bioactivated by this enzyme [8-14].

RH1 is a compound selected for clinical development by the Cancer Research Campaign (CRC) and the NCI, and after its preclinical evaluation [15], it successfully underwent phase 1 evaluation [16].

Cells with elevated DT-diaphorase levels are generally more sensitive to bioreductive antitumour agents [10,17-19].

DT-diaphorase has been shown to be over-expressed in many cancerous tissues as opposed to normal tissues [20]. High levels of NQO1 gene expression are observed in liver, lung, colon and breast tumors in contrast to normal tissues of the same origin [21].

This enzyme is also ubiquitously expressed; a wide variation in NQO1 gene expression has been noted among various human tissues [22]; its overexpression has been described in isolated normal cells, i.e. podocytes [23] and cells of human reproductive system (Leydig's cells) [24]; this observation may explain some quinones-related clinical toxicities, such as infertility and kidney failure.

Analyses of RNA indicate levels of NQ01 gene expression in tumours and in the tissue surrounding the tumours of patients with carcinoma that are 20- to 50-times higher than in normal individuals $[25,26]$.

A dose correlation between DT-diaphorase expression explored by immunological methods and enzyme activity has been demonstrated $[27,28]$. Since DT-diaphorase plays a major role in activating quinonecontaining anti-tumour agents in human carcinoma celi lines, the measurement of DT-diaphorase in clinical tumour samples is criticai in designing adjuvant or palliative chemotherapy. Compounds that can be bioactivated by DT-diaphorase are becoming of increasing interest [12,15,29-32,]. Because of the heterogeneous nature of DTdiaphorase expression, it is of primary interest to evaluate its expression and distribution in human normal and cancerous tissues. Surprisingly, DT-diaphorase has not been extensively investigated in human malignant melanomas or more generally in pigmentproducing cells that are known to generate considerable amounts of ortho-quinones [33]. Very little has been previously reported on the level of expression of DT-diaphorase in human malignant melanomas of the skin. By a spectrophotometric method, a previous study detected high DT-diaphorase activity in melanoma cell cultures, in comparison to melanocytes isolated from normal skin or pigmented congenital naevus [33]. Another study analysed pathology specimens of conjunctival melanomas and primary acquired melanosis for DTdiaphorase expression by immunohistochemistry [34]. DT-diaphorase was detected in every examined section of primary acquired melanosis 
(cell-to-cell variability in the staining) and of melanoma of the conjunctiva (uniform staining). Interestingly, mitomycin $\mathrm{C}$ has been used in the treatment of both acquired melanosis and melanomas of the conjunctiva, suggesting that DT-diaphorase may play a role in the bioactivation of mitomycin $\mathrm{C}$ in these tumours. In our study, we performed an immunohistochemical analysis of DT-diaphorase expression in human primary malignant melanotic melanomas of the skin.

\section{Materials and Methods}

\section{Human tissues}

Archival samples of formalin-fixed paraffin-embedded tissues were supplied by the Institute of Pathology of Southern Switzerland, Locarno, Switzerland.

We analysed

- Ten bioptic samples of superficial spreading human malignant melanoma

- Ten bioptic samples of locally invasive human malignant melanomas

\section{Methods}

We performed an immunohistochemical analysis for the detection of DTD on tissue sections using anti-DTD antibodies.

\section{Antibodies and Reagents}

Anti-DTD monoclonal antibody (IgG1)-secreting hybridomas (clones A180 and B 771) were derived from a BALB-c mouse immunized with purified recombinant human DTD protein. All hybridoma cell lines were grown in spinner flasks in RPMI medium containing 50 units $/ \mathrm{ml}$ penicillin, $50 \mu \mathrm{g} / \mathrm{ml}$ streptomycin, $1 \% \mathrm{~L}$ glutamine and $10 \%$ fetal bovine serum in $5 \% \mathrm{CO}_{2}$ at $37^{\circ} \mathrm{C}$ to a concentration of $10^{6}$ cells $/ \mathrm{ml}$. Hybridoma tissue culture supernatants were prepared by centrifugation at $1800 \mathrm{rpm}$ for $10 \mathrm{~min}$ and then stored at $-80^{\circ} \mathrm{C}$.

Prior to use supernatants were centrifuged at $14,000 \mathrm{rpm}$ for 5 minutes. We demonstrated specificity of our proprietary antibody by pre-absorbing it with antigen (human recombinant DTD), and showing that immunohistochemical staining was completely blocked. We also performed a Western analysis on tissue extracts to confirm immunohistochemical staining specificity. Non-human reactive monoclonal mouse antibodies produced in tissue culture, subclass $\lg \mathrm{G} 1$, were used as negative control reagent (Mouse lgG1 Negative Control Code No. X0931 DAKO A/S, Denmark).

\section{Immunohistochemical method}

Immunohistochemistry was performed on tissue sections $(3 \mu \mathrm{m})$ cut from archival paraffin blocks. Sections were de-paraffinized in xylene and rehydrated through graded alcohol to running water, then placed in citrate buffer pH 6.0 and microwaved for two 3 min cycles. Endogenous peroxidase activity was blocked by adding Peroxidase Blocking Agent (DAKO En Vision Kit, Carpinteria, CA 93013 USA). Non-specific binding was blocked by adding $20 \%$ normal rabbit serum. Serial sections of each tissue sample were then incubated with either anti-DTD or control antibodies for 30 minutes at room temperature. The secondary antibody was added for 30 minutes
(DAKOKIT, labelled Polymer HRP anti-mouse: peroxidase labelled polymer conjugated to goat anti-mouse immunoglobulins). Immunodetection was performed using a substrate-chromogen solution (DAKOKIT, hydrogen peroxide and 3,3'-diaminobenzidine chromogen). Slides were counterstained with haematoxylin, dehydrated through graded alcohols, mounted and photographed.

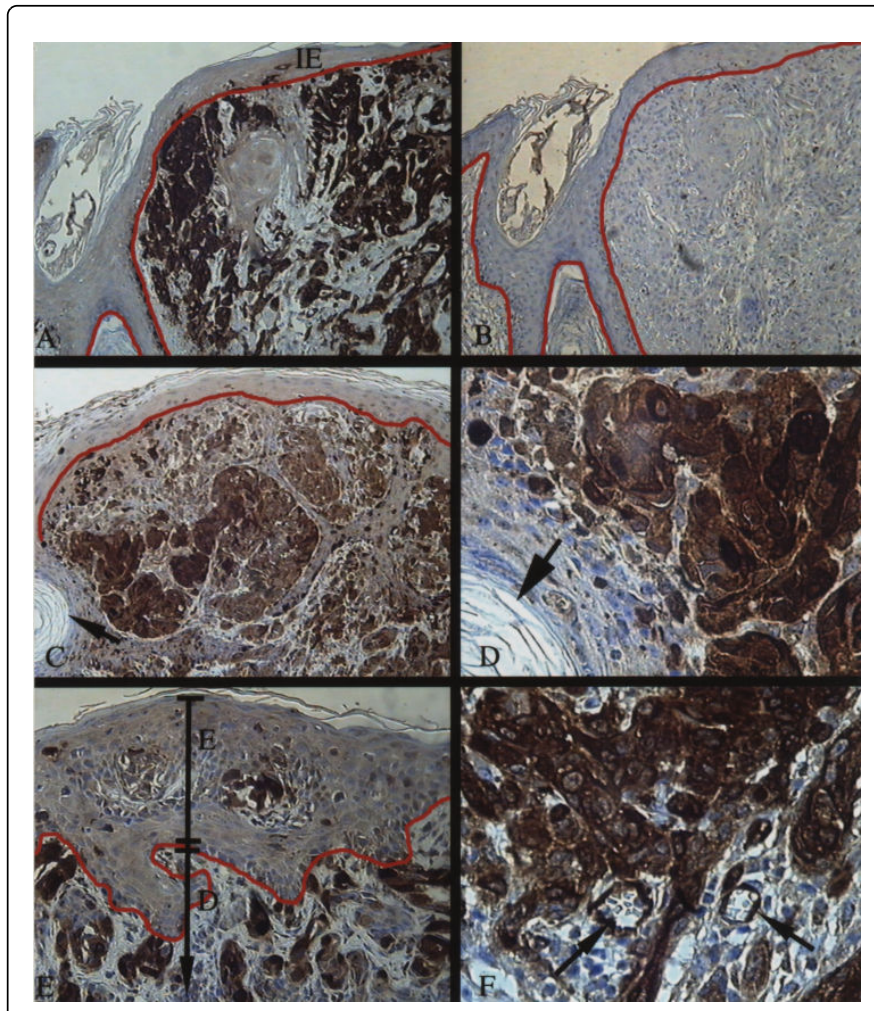

Figures 1A-1F: shows the immunohistochemical detection of DTdiaphorase in superficial spreading (epidermal invasion) malignant melanomas of the skin: Figure 1A: very strong expression of DTdiaphorase in malignant melanoma cells clusters in epidermis (E). Dermis (D) is not invaded (red line dividing epidermis from dermis). Figure 1B: negatif control of Figure 1A (HE staining). Figures 1C-D: cancer cells clusters (arrows) in epidermis (E). Higher magnifications of Figure1A. Figure 1E-F: another sample showing the very strong expression of DT-diaphorase in superficial spreading malignant melanoma cells invading the epidermis (E) but not the dermis (D). (Figure E, low magnification; figure F, high magnification).

\section{Scoring of DTD immunostaining}

The intensity of immunostaining of DTD (brown staining) was visually scored as 0 (negative), +1 (very weak), +2 (weak), +3 (strong), +4 (very intense) as previously reported for human lung cancers [35].

\section{Results}

All samples analysed were suitable for immunohistochemical analysis of DTD expression.

Superficial spreading malignant melanomas: in this histological variant cancer cells invade the epidermis but not the dermis. There was a very strong (score +4$)$ DTD expression in tumoral cells of all 
Citation: Zappa F, Ward T, Pedrinis E, Mc Gown A, Thatcher N (2014) NAD(P)H:Quinone Oxidoreductase 1 Expression in Human Primary Melanotic Melanomas of the Skin. J Cytol Histol 5: 259. doi:10.4172/2157-7099.1000259

Page 3 of 5

samples analysed (Figures 1A-1F). DTD expression in adjacent normal skin was very low to low $($ score $+1 /+2)$.

Invasive malignant melanomas: in this histological variant cancer cells infiltrate the dermis of the skin. There was a very strong (score +4 ) DTD expression in tumoral cells of all samples analysed (Figure 2A-2F). Endothelial lining of peri-tumoral vessels also showed strong to very strong (score $+3 /+4$ ) staining for DTD (Figure $2 \mathrm{~F}$ ).

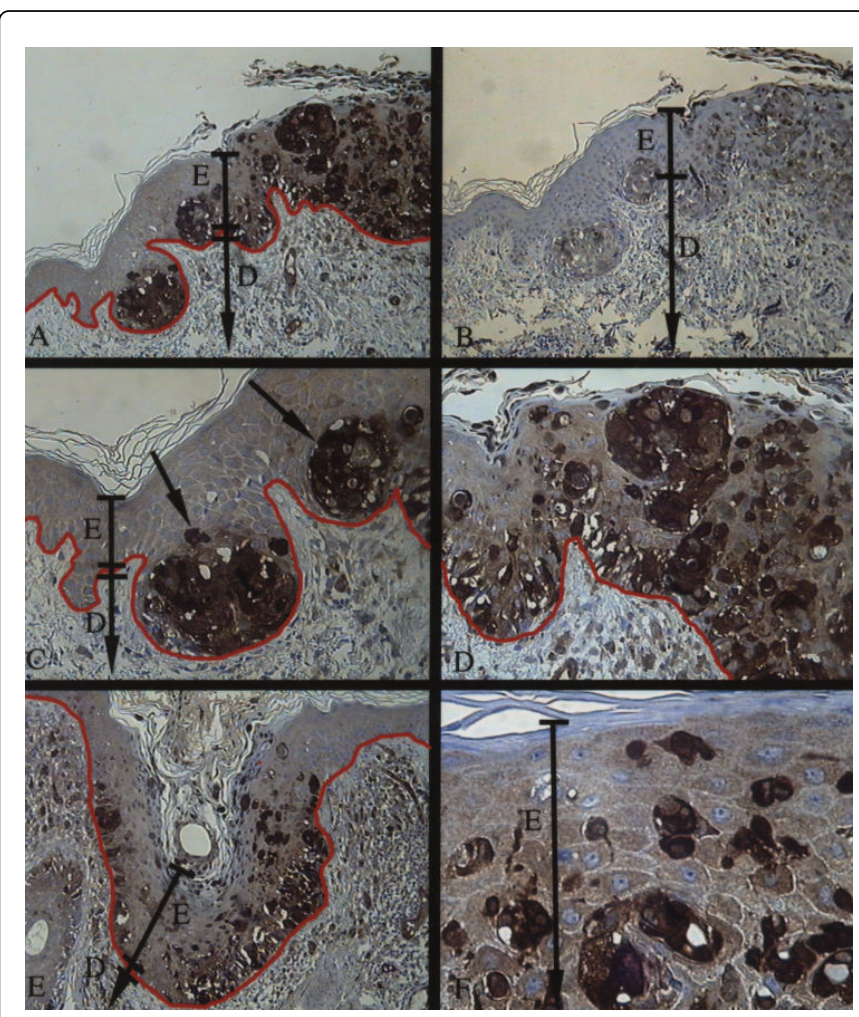

Figures 2A-2F: shows the immunohistochemical detection of DTdiaphorase in invasive malignant melanomas of the skin: Figure 2A: very strong expression of DT-diaphorase in malignant melanoma cells invading the dermis (red line separates epidermis (E) from dermis). Figure 2B: negatif control of Figure 2A. Figures 2C-D: another sample showing dermal infiltration of malignant melanoma cells, low (Figure 2C) and high magnification (figure 2D). A section of an hair follicle is shown (arrow). Figure 2E: another sample showing the strong expression of DT-diaphorase in cancer cells clusters invading the dermis (D). Figure 2F: strong expression of DT-diaphorase in malignant melanoma cells in the dermis (high magnification). Endothelial lining of dermal capillaries (arrows) also shows strong DT-diaphorase expression.

Normal skin: DTD expression was very weak to weak (score $+1 /+2)$ in all epidermal layers and in normal melanocytes, and absent in dermis and hypodermis (score 0 ) (Figure $3 \mathrm{~A}$ ). A strong to very strong (score $+3 /+4)$ staining for DTD was seen in sebaceous and sweat glands (Figure 3C-3D), and a strong to very strong staining (score $+3 /+4)$ was seen in endothelial lining of dermal vessels $($ score $+3 /+4)$ (Figure 3A). Interestingly, in one sample we did observe a well circumscribed epidermal area of strong DTD expression (Figure 3B). This could reflect a focal, protective response of the skin to external noxious agents.
There was no immunostaining in control sections when nonspecific antibodies were used (Figures 1B, 2B, and 3D).

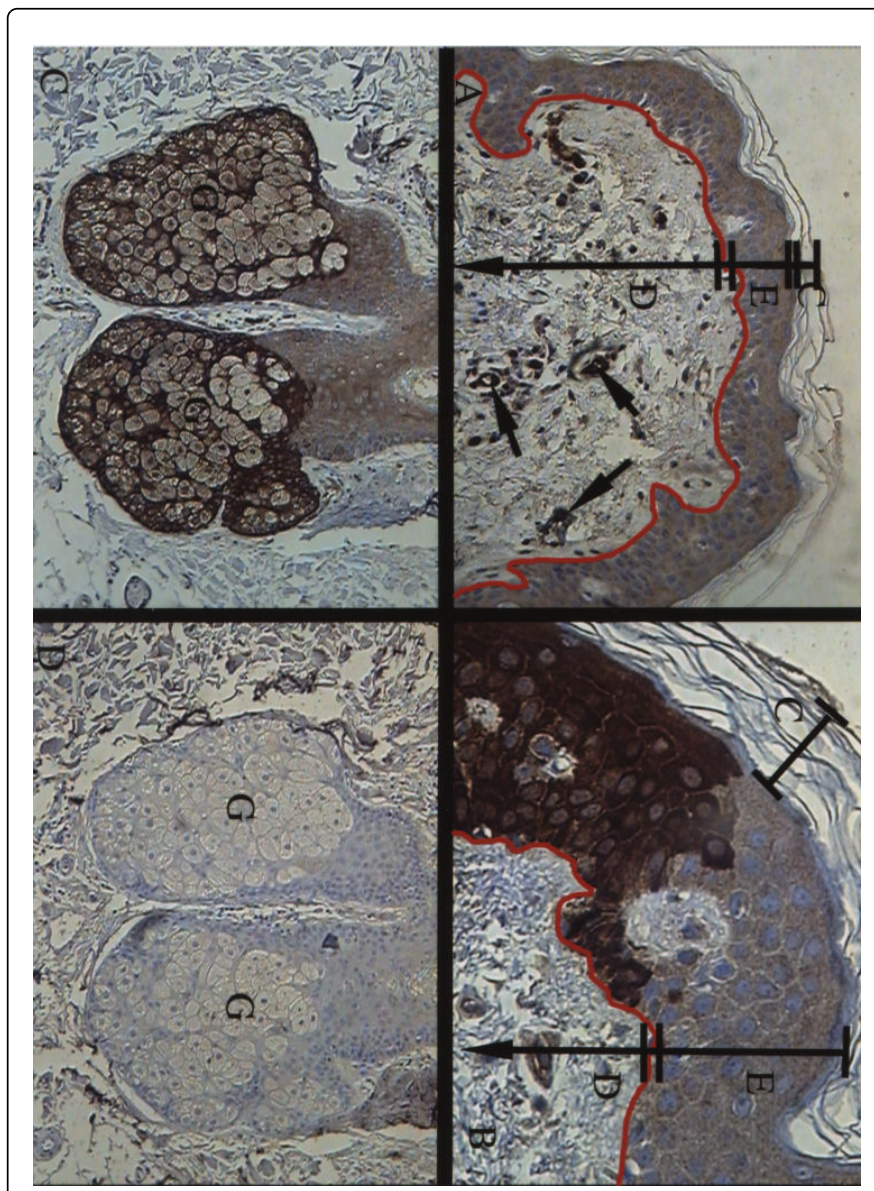

Figures 3A-3D: shows the immunohistochemical detection of DTdiaphorase in normal skin: Figure 3A: weak DT-diaphorase expression in normal epidermis (E). No DT-diaphorase expression is seen in dermis (D). (C=stratum corneum). Figure 3B: cell-to-cell variability of DT-diaphorase expression in normal skin. (E=epidermis). Figures 3C-D: very strong expression of DTdiaphorase in sebaceous glands $(\mathrm{G})$. (Figure $\mathrm{D}=$ =negatif control).

\section{Discussion}

Malignant melanoma is a tumor of melanocytes, cells derived embryologically from the neural crest. Most melanocytes are located in the basal layer of the epidermis, and produce melanin pigment, which is released into the epidermis and is responsible for skin colour. In fair-skinned individuals, melanocytes are subjected to considerable irradiation by visible and ultraviolet light. There is good epidemiological evidence from case-control studies to implicate sun exposure as a major causative factor for human melanoma [36]. The increasing incidence of malignant melanoma and the sparse availability of therapeutical resources implies the need to find new strategies to optimize its diagnosis and treatment. The prognosis of malignant melanoma is based on the stage of invasion at diagnosis, and is therefore strictly dependent on the ability of the pathologist to determine precisely the thickness of the melanoma (according to Breslow) and the level of invasion of the dermis. Other histological 
and cytological factors with prognostic significance are the presence of ulceration and the number of mitosis, as well as the presence of satellite metastasis and in-transit metastasis around the tumor. The presence and the number of lymph nodes and of distant metastases are also of high prognostic relevance. Immunohistochemistry is the most valuable technique in diagnostic pathology. Many immunohistochemical markers of melanocytic lesions are available, some for diagnostic use, others with prognostic value. The most widely used melanocytic immunohistochemical markers in melanoma diagnosis on paraffin-embedded tissue blocks are the antigens S100 (antibody S100) [37,38], gp 100 (antibodies HMB-45 and NKI-beteb), tyrosinase (antibody T311) and the melanoma antigen recognized by $\mathrm{T}$ cells, MART-1 (antibody A103) [39-47]. These antibodies are relevant not only for their histo-pathological diagnostic utility, but also with respect to the development of new anti-tumoral immunotherapeutical approaches and for screening potential candidates for these immunotherapies [48-50]. It is known that peptides derived from the antigens MART-1, tyrosinase and gp100 can generate immune responses because they are presented to T-lymphocytes (cytolytic Tcell-mediated immune response) [47,50,51]. In our study, a very strong expression of DT-diaphorase was found in malignant melanoma tumoral cells but not in normal skin. Interestingly, endothelial lining of vessels also expressed high levels of DTdiaphorase, revealing a potentially double cytotoxic action of DTDactivated compounds, both on tumor cells and vessels. In fact, cells with elevated DT-diaphorase levels are intrinsically more sensitive to bioreductive antitumour agents such as Mitomicyn C, Streptonigrin or $\mathrm{RH} 1$, because of activation of these prodrugs upon reduction by DTdiaphorase. This reduction produces potent cytotoxic compounds that cross-link DNA and cause cell death. Indeed it is the increased expression of DT-diaphorase in tumor tissue that is used as a selective target for the design of new anti-cancer drugs. These results validate the interest in malignant melanomas as targets for DTD-activated antitumour quinones and, in addition, propose that DT-diaphorase may be a novel immunohistochemical marker for use in determining the intra-epidermal and dermal extent of human malignant melanoma of the skin. The specificity of this new potential marker in distinguishing malignant melanocytic from benign melanocytic lesions and in evaluating malignant melanoma metastasis needs to be further evaluated.

\section{Acknowledgments}

Anti-DTD antibodies were a generous gift from Professor David Ross, Department of Pharmaceutical Sciences, School of Pharmacy and Cancer Center, University of Colorado Health Sciences Center, Denver, Colorado.

Francesco Zappa's research is supported by an ESMO (European Society for Medical Oncology) grant.

\section{References}

1. Benson AM, Hunkeler MJ, Talalay $P$ (1980) Increase of $\mathrm{NAD}(\mathrm{P}) \mathrm{H}$ :quinone reductase by dietary antioxidants: possible role in protection against carcinogenesis and toxicity. Proc Natl Acad Sci U S A 77: 5216-5220.

2. Talalay P, De Long MJ, Prochaska HJ (1988) Identification of a common chemical signal regulating the induction of enzymes that protect against chemical carcinogenesis. Proc Natl Acad Sci U S A 85: 8261-8265.

3. Trush MA, Twerdok LE, Rembish SJ, Zhu H, Li Y (1996) Analysis of target cell susceptibility as a basis for the development of a chemoprotective strategy against benzene-induced hematotoxicities. Environ Health Perspect 104 Suppl 6: 1227-1234.

4. Lind C, Hochstein P, Ernster L (1982) DT-diaphorase as a quinone reductase: a cellular control device against semiquinone and superoxide radical formation. Arch Biochem Biophys 216: 178-185.

5. Thor H, Smith MT, Hartzell P, Bellomo G, Jewell SA, et al. (1982) The metabolism of menadione (2-methyl-1,4-naphthoquinone) by isolated hepatocytes. A study of the implications of oxidative stress in intact cells. J Biol Chem 257: 12419-12425.

6. Chesis PL, Levin DE, Smith MT, Ernster L, Ames BN (1984) Mutagenicity of quinones: pathways of metabolic activation and detoxification. Proc Natl Acad Sci U S A 81: 1696-1700.

7. Ross D, Siegel D (2004) NAD(P)H:quinone oxidoreductase 1 (NQO1, DT-diaphorase), functions and pharmacogenetics. Methods Enzymol 382: 115-144.

8. Gibson NW, Hartley JA, Butler J, Siegel D, Ross D (1992) Relationship between DT-diaphorase-mediated metabolism of a series of aziridinylbenzoquinones and DNA damage and cytotoxicity. Mol Pharmacol 42: 531-536.

9. Lee CS, Hartley JA, Berardini MD, Butler J, Siegel D, et al. (1992) Alteration in DNA cross-linking and sequence selectivity of a series of aziridinylbenzoquinones after enzymatic reduction by DT-diaphorase. Biochemistry 31: 3019-3025.

10. Malkinson AM, Siegel D, Forrest GL, Gazdar AF, Oie HK, et al. (1992) Elevated DT-diaphorase activity and messenger RNA content in human non-small cell lung carcinoma: relationship to the response of lung tumor xenografts to mitomycin CÅ,. Cancer Res 52: 4752-4757.

11. Berardini MD, Souhami RL, Lee CS, Gibson NW, Butler J, et al. (1993) Two structurally related diaziridinylbenzoquinones preferentially crosslink DNA at different sites upon reduction with DT-diaphorase. Biochemistry 32: 3306-3312.

12. Ross D, Beall H, Traver RD, Siegel D, Phillips RM, et al. (1994) Bioactivation of quinones by DT-diaphorase, molecular, biochemical, and chemical studies. Oncol Res 6: 493-500.

13. Beall HD, Murphy AM, Siegel D, Hargreaves RH, Butler J, et al. (1995) Nicotinamide adenine dinucleotide (phosphate): quinone oxidoreductase (DT-diaphorase) as a target for bioreductive antitumor quinones: quinone cytotoxicity and selectivity in human lung and breast cancer cell lines. Mol Pharmacol 48: 499-504.

14. Fourie J, Oleschuk CJ, Guziec F Jr, Guziec L, Fiterman DJ, et al. (2002) The effect of functional groups on reduction and activation of quinone bioreductive agents by DT-diaphorase. Cancer Chemother Pharmacol 49: 101-110.

15. Ward TH, Danson S, McGown AT, Ranson M, Coe NA, et al. (2005) Preclinical evaluation of the pharmacodynamic properties of 2,5diaziridinyl-3-hydroxymethyl-6-methyl-1,4-benzoquinone. Clin Cancer Res 11: 2695-2701.

16. Danson SJ, Johnson P, Ward TH, Dawson M, Denneny O, et al. (2011) Phase I pharmacokinetic and pharmacodynamic study of the bioreductive drug RH1. Ann Oncol 22: 1653-1660.

17. O'Dwyer PJ, Szarka CE, Yao KS, Halbherr TC, Pfeiffer GR, et al. (1996) Modulation of gene expression in subjects at risk for colorectal cancer by the chemopreventive dithiolethione oltipraz. J Clin Invest 98: 1210-1217.

18. Begleiter A, Leith MK, Curphey TJ, Doherty GP (1997) Induction of DTdiaphorase in cancer chemoprevention and chemotherapy. Oncol Res 9: 371-382.

19. Clapper ML, Szarka CE (1998) Glutathione S-transferases--biomarkers of cancer risk and chemopreventive response. Chem Biol Interact 111-112: $377-88$.

20. Schlager JJ, Powis G (1990) Cytosolic NAD(P)H:(quinoneacceptor)oxidoreductase in human normal and tumor tissue: effects of cigarette smoking and alcohol. Int J Cancer 45: 403-409.

21. Belinsky M, Jaiswal AK (1993) NAD(P)H:quinone oxidoreductase1 (DTdiaphorase) expression in normal and tumor tissues. Cancer Metastasis Rev 12: 103-117. 
22. Joseph P, Xie T, Xu Y, Jaiswal AK (1994) NAD(P)H:quinone oxidoreductase1 (DT-diaphorase): expression, regulation, and role in cancer. Oncol Res 6: 525-532.

23. Zappa F, Ward T, Pedrinis E, Butler J, McGown A (2003) NAD(P)H: quinone oxidoreductase 1 expression in kidney podocytes. J Histochem Cytochem 51: 297-302.

24. Zappa F, Ward T, Butler J, Pedrinis E, McGown A (2001) Overexpression of $\mathrm{NAD}(\mathrm{P}) \mathrm{H}$ :quinone oxidoreductase 1 in human reproductive system. J Histochem Cytochem 49: 1187-1188.

25. Cresteil T, Jaiswal AK (1991) High levels of expression of the $\mathrm{NAD}(\mathrm{P}) \mathrm{H}$ :quinone oxidoreductase (NQO1) gene in tumor cells compared to normal cells of the same origin. Biochem Pharmacol 42: 1021-1027.

26. Phillips RM, de la Cruz A, Traver RD, Gibson NW (1994) Increased activity and expression of NAD(P)H:quinone acceptor oxidoreductase in confluent cell cultures and within multicellular spheroids. Cancer Res 54: 3766-3771.

27. Marín A, López de Cerain A, Hamilton E, Lewis AD, Martinez-Peñuela JM, et al. (1997) DT-diaphorase and cytochrome B5 reductase in human lung and breast tumours. Br J Cancer 76: 923-929.

28. Mikami K, Naito M, Ishiguro T, Yano H, Tomida A, et al. (1998) Immunological quantitation of DT-diaphorase in carcinoma cell lines and clinical colon cancers: advanced tumors express greater levels of DTdiaphorase. Jpn J Cancer Res 89: 910-915.

29. Siegel D, Gibson NW, Preusch PC, Ross D (1990) Metabolism of mitomycin C by DT-diaphorase: role in mitomycin C-induced DNA damage and cytotoxicity in human colon carcinoma cells. Cancer Res 50: 7483-7489.

30. Ross D, Siegel D, Beall H, Prakash AS, Mulcahy RT, et al. (1993) DTdiaphorase in activation and detoxification of quinones. Bioreductive activation of mitomycin C. Cancer Metastasis Rev 12: 83-101.

31. Workman P (1994) Enzyme-directed bioreductive drug development revisited: a commentary on recent progress and future prospects with emphasis on quinone anticancer agents and quinone metabolizing enzymes, particulatly DT-diaphorase. Oncol Res 6: 461-464.

32. Winski SL, Hargreaves RH, Butler J, Ross D (1998) A new screening system for $\mathrm{NAD}(\mathrm{P}) \mathrm{H}$ :quinone oxidoreductase (NQO1)-directed antitumor quinones: identification of a new aziridinylbenzoquinone, RH1, as a NQO1-directed antitumor agent. Clin Cancer Res 4: 3083-3088.

33. Smit NP, Hoogduijn MJ, Riley PA, Pavel S (1999) Study of DTdiaphorase in pigment-producing cells. Cell Mol Biol (Noisy-le-grand) 45: 1041-1046.

34. Wilson MW, Schelonka LP, Siegel D, Meininger A, Ross D (2001) Immunohistochemical localization of $\mathrm{NAD}(\mathrm{P}) \mathrm{H}$ :quinone oxidoreductase in conjunctival melanomas and primary acquired melanosis. Curr Eye Res 22: 348-352

35. Siegel D, Franklin WA, Ross D (1998) Immunohistochemical detection of $\mathrm{NAD}(\mathrm{P}) \mathrm{H}$ :quinone oxidoreductase in human lung and lung tumors. Clin Cancer Res 4: 2065-2070.
36. Elwood JM (1992) Melanoma and sun exposure: contrasts between intermittent and chronic exposure. World J Surg 16: 157-165.

37. Gaynor R, Herschman HR, Irie R, Jones P, Morton D, et al. (1981) S100 protein: a marker for human malignant melanomas? Lancet 1: 869-871.

38. Cochran AJ, Wen DR (1985) S-100 protein as a marker for melanocytic and other tumours. Pathology 17: 340-345.

39. Chen YT, Stockert E, Tsang S, Coplan KA, Old LJ (1995) Immunophenotyping of melanomas for tyrosinase: implications for vaccine development. Proc Natl Acad Sci U S A 92: 8125-8129.

40. Marincola FM, Hijazi YM, Fetsch P, Salgaller ML, Rivoltini L, et al. (1996) Analysis of expression of the melanoma-associated antigens MART-1 and gp100 in metastatic melanoma cell lines and in in situ lesions. J Immunother Emphasis Tumor Immunol 19: 192-205.

41. De Vries TJ, Fourkour A, Wobbes T, Verkroost G, Ruiter DJ, et al. (1997) Heterogeneous expression of immunotherapy candidate proteins gp100, MART-1 and tyrosinase in human melanoma cell lines and in human melanocytic lesions. Cancer Res 67: 3223-3229.

42. Kageshita T, Kawakami Y, Hirai S, Ono T (1997) Differential expression of MART-1 in primary and metastatic melanoma lesions. J Immunother 20: 460-465.

43. Nicotra MR, Nisticò P, Mangoni A, Di Filippo F, Marincola FM, et al. (1997) Melan-A/MART-1 antigen expression in cutaneous and ocular melanomas. J Immunother 20: 466-469.

44. Busam KJ, Chen YT, Old LJ, Stockert E, Iversen K, et al. (1998) Expression of melan-A (MART1) in benign melanocytic nevi and primary cutaneous malignant melanoma. Am J Surg Pathol 22: 976-982.

45. Jungbluth AA, Busam KJ, Gerald WL, Stockert E, Coplan KA, et al. (1998) A103: An anti-melan-a monoclonal antibody for the detection of malignant melanoma in paraffin-embedded tissues. Am J Surg Pathol 22: 595-602.

46. Kaufmann O, Koch S, Burghardt J, Audring H, Dietel M (1998) Tyrosinase, melan-A and KBA62 as markers for the immunohistochemical identification of metastatic amelanotic melanomas on paraffin sections. Mod Pathol 11: 740- 746.

47. Orosz Z (1999) Melan-A/Mart-1 expression in various melanocytic lesions and in non-melanocytic soft tissue tumours. Histopathology 34: 517-525.

48. Cormier JN, Abati A, Fetsch P, Hijazi YM, Rosenberg SA, et al. (1998) Comparative analysis of the in vivo expression of tyrosinase, MART-1/ Melan-A, and gp100 in metastatic melanoma lesions: implications for immunotherapy. J Immunother 21: 27-31.

49. de Vries TJ, Trancikova D, Ruiter DJ, van Muijen GN (1998) High expression of immunotherapy candidate proteins gp100, MART-1, tyrosinase and TRP-1 in uveal melanoma. Br J Cancer 78: 1156-1161.

50. Riker A, Cormier J, Panelli M, Kammula U, Wang E, et al. (1999) Immune selection after antigen-specific immunotherapy of melanoma. Surgery 126: 112-120.

51. Boon T (1993) Teaching the immune system to fight cancer. Sci Am 268: 82-89. 